\title{
Biodegradability of Visco 2000-Sae20 (V20) and Superv-Sae20 (S20) Engine Oils by Fungi Isolated From Polluted Soil
}

\author{
E. M. Omoghie ${ }^{1,3}$ U. Udochukwu ${ }^{2}$ A. O. Oshionebo ${ }^{3}$ \\ ${ }^{I}$ Department Of Microbiology, Faculty Of Life Science University of \\ Port Harcourt, River State, Nigeria \\ ${ }^{2}$ Department of Bioscience, College of Natural and Applied Sciences, Salem University-lokoja, Kogi State, \\ Nigeria \\ ${ }^{3}$ Department Of Microbiology, Faculty Of Life Science University Of Benin, Edo State, Nigeria
}

\begin{abstract}
Biodegradability of visco 2000-SAE20 (V20) and superV-SAE20 (S20) engine oils by fungi isolated from soil polluted soil was investigated for a period of twenty-eight (28) days. Two different samples of the engine oils; Visco 2000-SAE20 (V20) and Super-V SAE 20 (S20) were investigated. Soil from a mechanic workshop in Aluu community near University of Port Harcourt served as seed for the biodegradation. The study was carried out at room temperature $\left(28-29^{\circ} \mathrm{C}\right)$. The $\mathrm{pH}$ of the test systems ranged from 6.2 to 4.9 where the heterotrophic fungal count for the first day were $2.8 \times 10^{2}$ and $2.2 \times 10^{3}$ for V2O and S20 the corresponding count in day 28 were $2.7 \times 10^{4}$ and $4.2 \times 10^{3}$ in colony forming unit per milliliters $(\mathrm{cfu} / \mathrm{ml})$. The hydrocarbon utilizing fungal isolates were identified as Aspergillus, Fusarium, Mucor, Penicillium, Rhizopus, and Saccharomyces. The physicochemical analysis showed that nitrate, phosphate, sulphate, biochemical oxygen demand, (BOD), oil and grease content and total organic carbon (TOC) decreased with time.
\end{abstract}

Key Words: Engine Oils, Fungi, Polluted Soil, Total Organic Carbon (TOC) and Biochemical Oxygen Demand (BOD).

\section{Introduction}

All activities of using crude oil led to pollution risks that can be minimized, but not totally eliminated, causing several problems in the environment [15]. Engine oils can be classified based on their composition, chemical structure, molecular weight as well as their mode of application. High duty machines such as vehicle engines and some industrial machines used in food processing plants. Engine oil could either be mineral oil based or synthetic. Mineral oil based engine oils are derived from crude petroleum unlike the synthetic oil ones, which are products of chemical synthesis of hydrocarbon compounds. The chemical analysis of engine oils revealed that they contain a high content of polycyclic aromatic hydrocarbon (naphthalene, anthracene, phenols, and other derivatives) and a small fraction of aliphatic hydrocarbons $\left(\mathrm{nC}_{15}-\mathrm{nC}_{40}\right)$. Degradability of engine oils is crucial since most of the mechanical methods used to reduce hydrocarbon pollution is expensive, time consuming and depends mainly on soil excavation and treatment in a separate facilities. Though these treatments are effective but after burning, these soils lose their nutritional value and structure. These methods do not remove the contamination but only relocate the problem [8]. Microbial degradability is accomplished with the help of diverse group of microorganisms, particularly indigenous fungi present in soil which are ubiquitous in nature. These organisms can degrade a wide range of target constituents present in oil sludge [9]. The biodegradability of oil pollutants has been intensively studied in controlled conditions [3] and in open field experiments [4].The aim of this work is to determine the ability of indigenous fungi to utilize visco 2000-SAE20 (V20) and superV-SAE20 (S20) as carbon source and for growth thus degrading both petroleum fractions. In addition, the effect of physicochemical parameters influencing the hydrocarbon biodegradation was also investigated.

\section{Materials And Methods}

The soil samples were collected at Aluu community near the University of Port Harcourt, Rivers State, Nigeria. Soil samples for biological analysis were obtained from different points (about eight meters apart) and pooled together to form composite samples. Two types of unused engine oils produced by African Petroleum (AP) were obtained from the filling station located beside University of Port Harcourt road, Choba, Rivers State, Nigeria. The various types which include Visco 2000-SAE20W and Super V-SAE20W were aseptically taken to the laboratory for analysis. The soil sample was weighed and $10 \mathrm{~g}$ was dissolved in $90 \mathrm{ml}$ of distilled water to obtain a ten-fold dilution of the soil sample. Toxicity test was conducted to obtain non-toxic concentration. The test was conducted by measuring equal volumes $(10 \mathrm{ml})$ from the 10 -fold dilution of the soil sample into four conical flasks. Different volumes of $0.1 \mathrm{ml}, 1.0 \mathrm{ml}$ and 10.0 of the engine oils were transfer into the flasks. One of the flasks served as control which was free from engine oil. The volumes were made up to $100 \mathrm{ml}$ with sterile 
distilled water. This resulted to concentrations of $1 \mathrm{mg} / 1,0.1 \mathrm{mg} / 1$ and $0.01 \mathrm{mg} / 1$ of the engine oils. The cultures were incubated for 48 hours at room temperature. The non toxic concentrations of the engine oils were determined by plating out in an acidified Potato Dextrose Agar (PDA) at room temperature for five days. The sample inoculated with engine oil that produced similar counts with control after two days of incubation was taken as the non toxic concentration of the engine oil [11].

The biodegradation conditions of the experimental set up were monitored by withdrawing the samples before initiation of the experiment on the first day and subsequently at day 7, 14, 21 and 28 for microbiological and physicochemical analysis. Total heterotrophic fungal (THF) counts of the withdrawn samples were performed. Serial dilution using normal saline $(0.85 \%)$ as diluents was done and spread plate technique was adopted [13]. Acidified potato dextrose agar which is used for fungal growth was inoculated and incubated at room temperature for 5days. Vapour phase transfer method was adopted in estimating the population of hydrocarbon utilizing fungi [1]. Acidified mineral salt agar with a sterile filter paper (whatmann No. 1) saturated with the oil which supplied the hydrocarbon by vapour phase transfer to the inocula were incubated at room temperature for 8 days and the colonies were counted, taking note of each of the characteristic isolate. Physicochemical analyses were conducted, such as $\mathrm{pH}$, total organic carbon, biochemical oxygen demand (BOD), oil and grease analysis, alkalinity analysis, sulphate content, nitrate content and phosphate content to determine the rate of degradability of the oils through the investigation period.

Table 1. Non-toxic concentration determination $(\mathrm{cfu} / \mathrm{ml})$

\begin{tabular}{ccccc}
\hline S/N & \multicolumn{2}{c}{ Oil Sample } & \multicolumn{1}{c}{ Concentration $(\mathbf{m g} / \mathbf{l})$} & \multicolumn{1}{c}{$\mathbf{0 . 0 1}$} \\
\hline 1. & V20 & $5.22 \times 10^{2}$ & $8.42 \times 10^{2}$ & $2.11 \times 10^{3}$ \\
2. & S20 & $8.92 \times 10^{2}$ & $1.24 \times 10^{3}$ & $2.96 \times 10^{3}$ \\
3. & Control (without oil) $2.81 \times 10^{3}$ & & \\
\hline
\end{tabular}

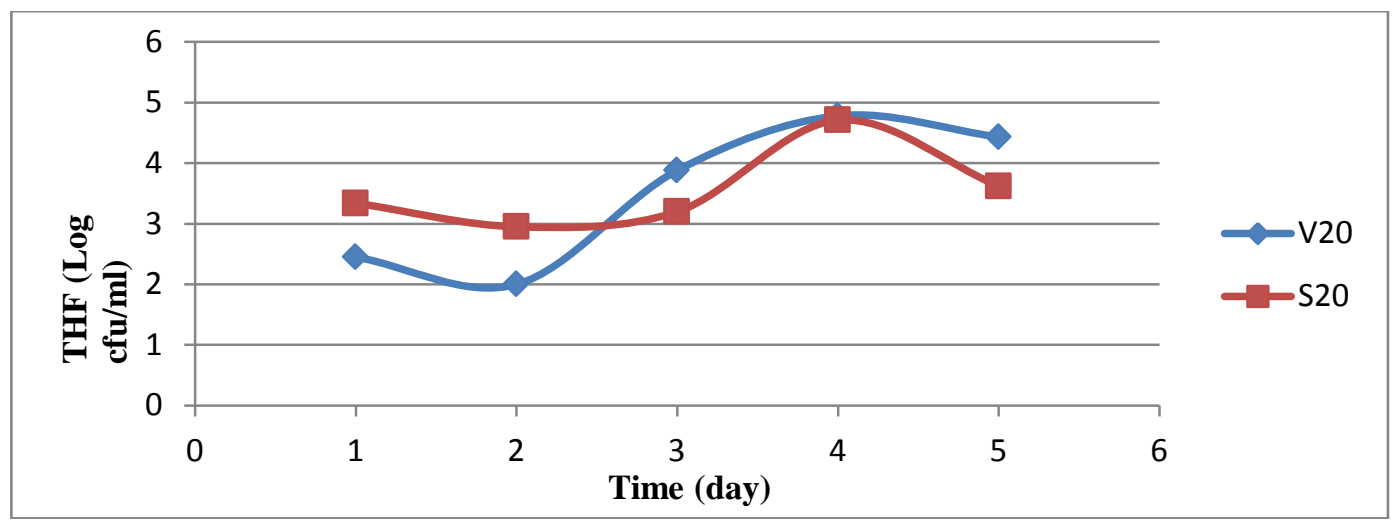

Fig 2. Change in total heterotrophic fungal count $(\log \mathrm{cfu} / \mathrm{ml})$ of the test system

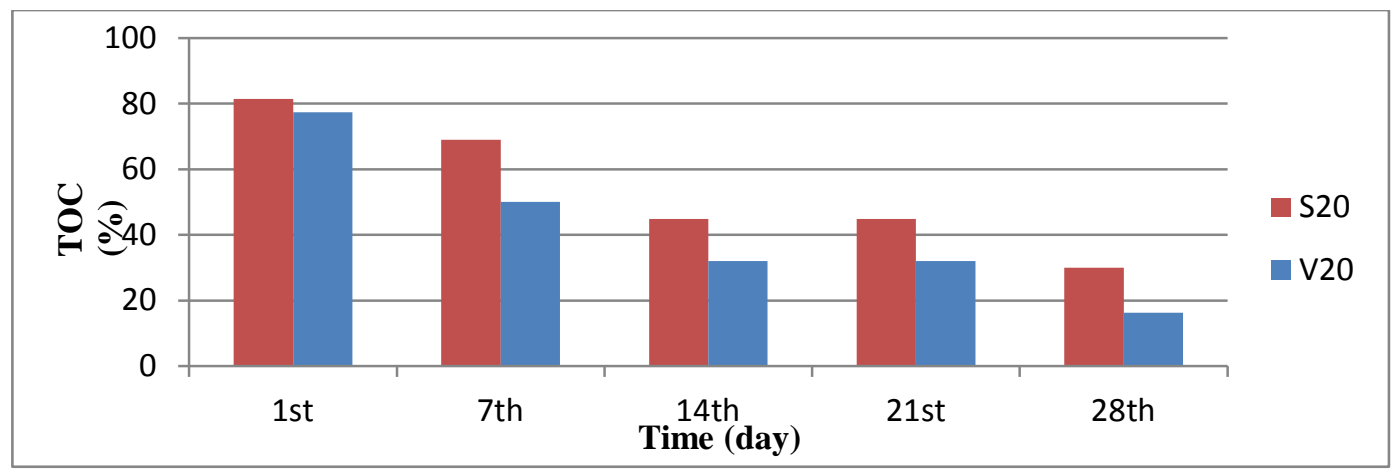

Fig 3. Change in percentage (\%) of total organic carbon of the test system 


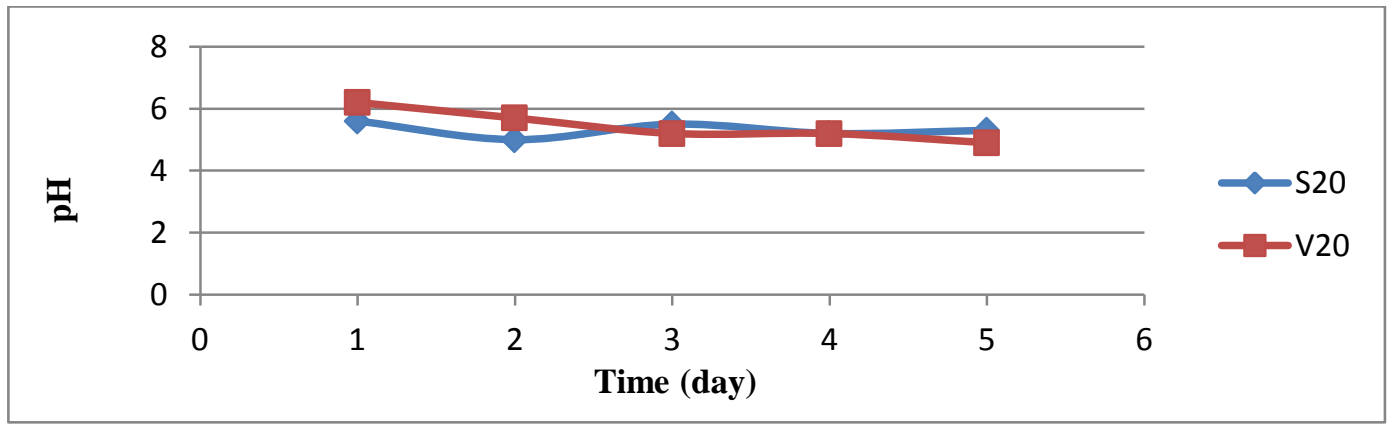

Fig. 4. Change in $\mathrm{pH}$ of the medium for the test systems.

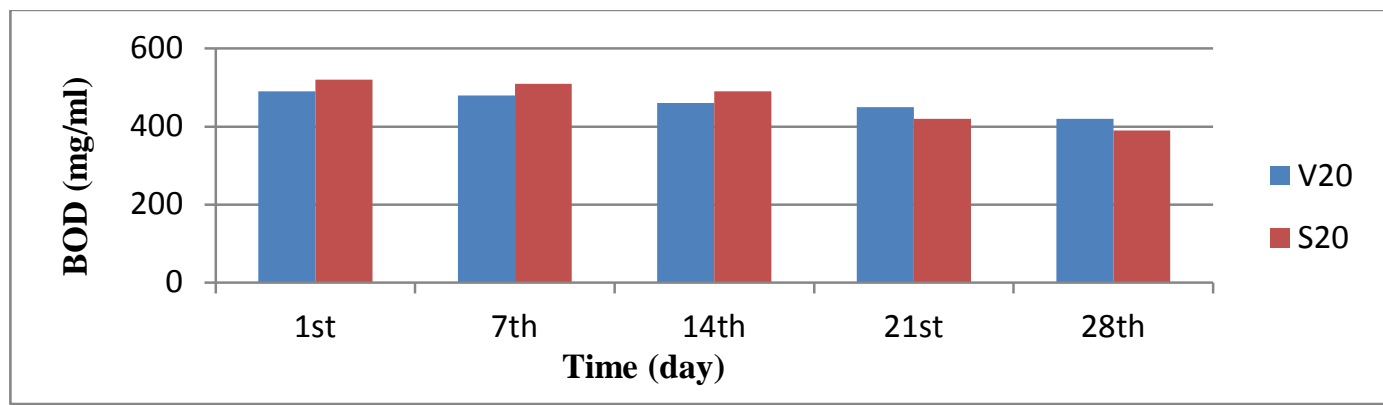

Fig. 5. Change in BOD OF the test systems.

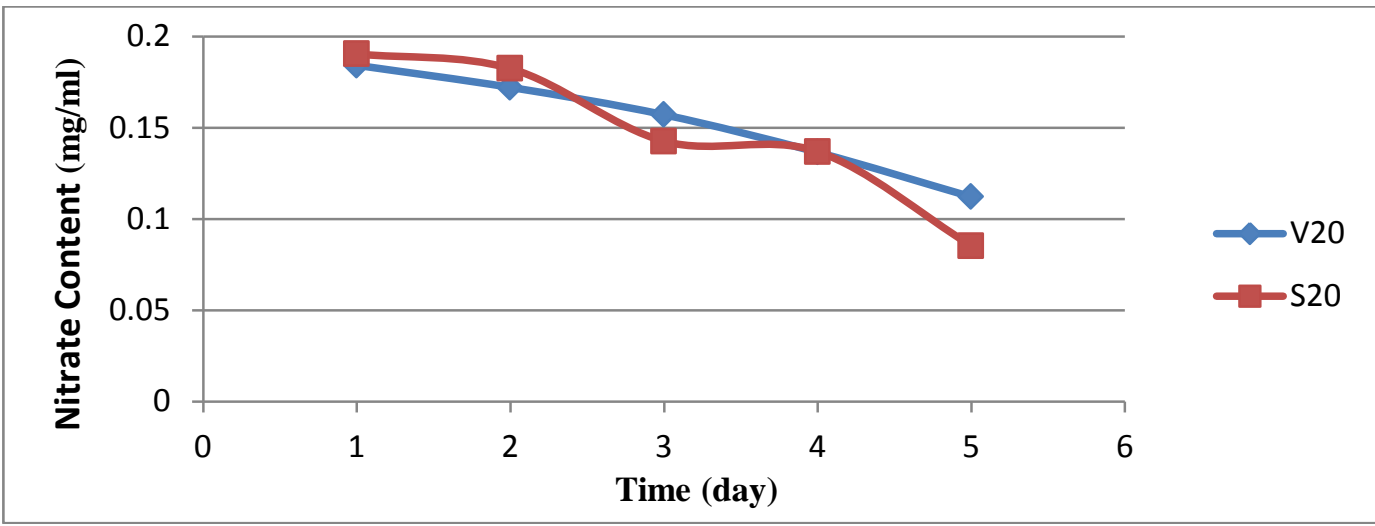

Fig. 6. Change in concentration of nitrate content for the test systems.

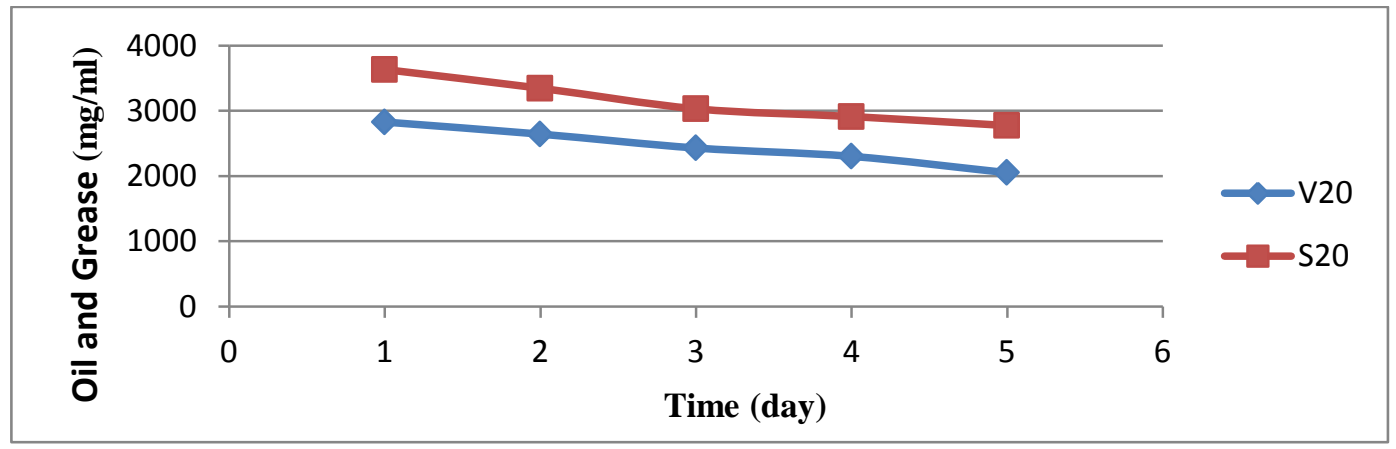

Fig. 7. Change in oil and grease of the test systems. 


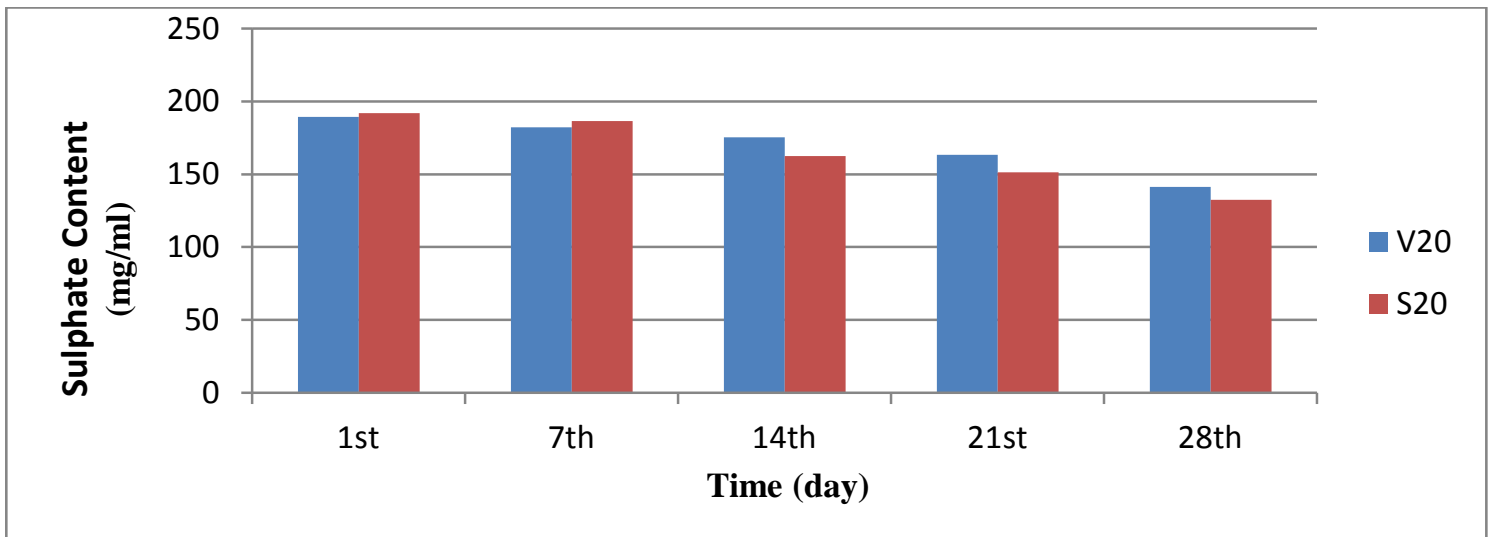

Fig. 8. Change in the concentration of sulphate content of the test systems.

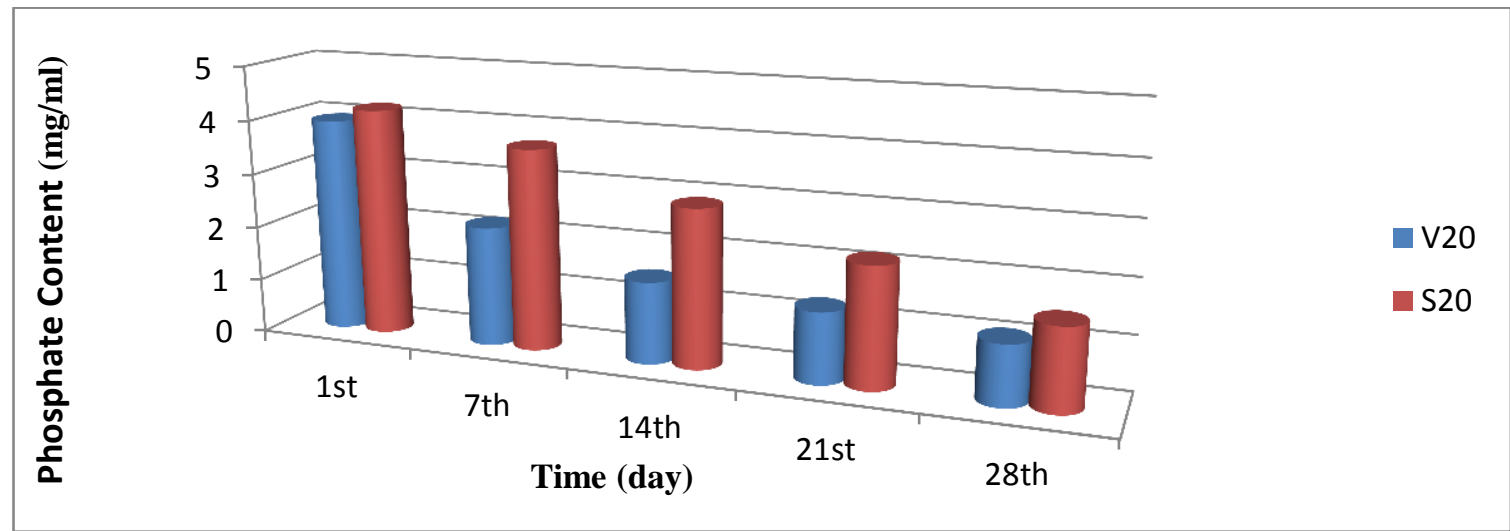

Fig. 9. Change in the concentration of phosphate content of the test systems.

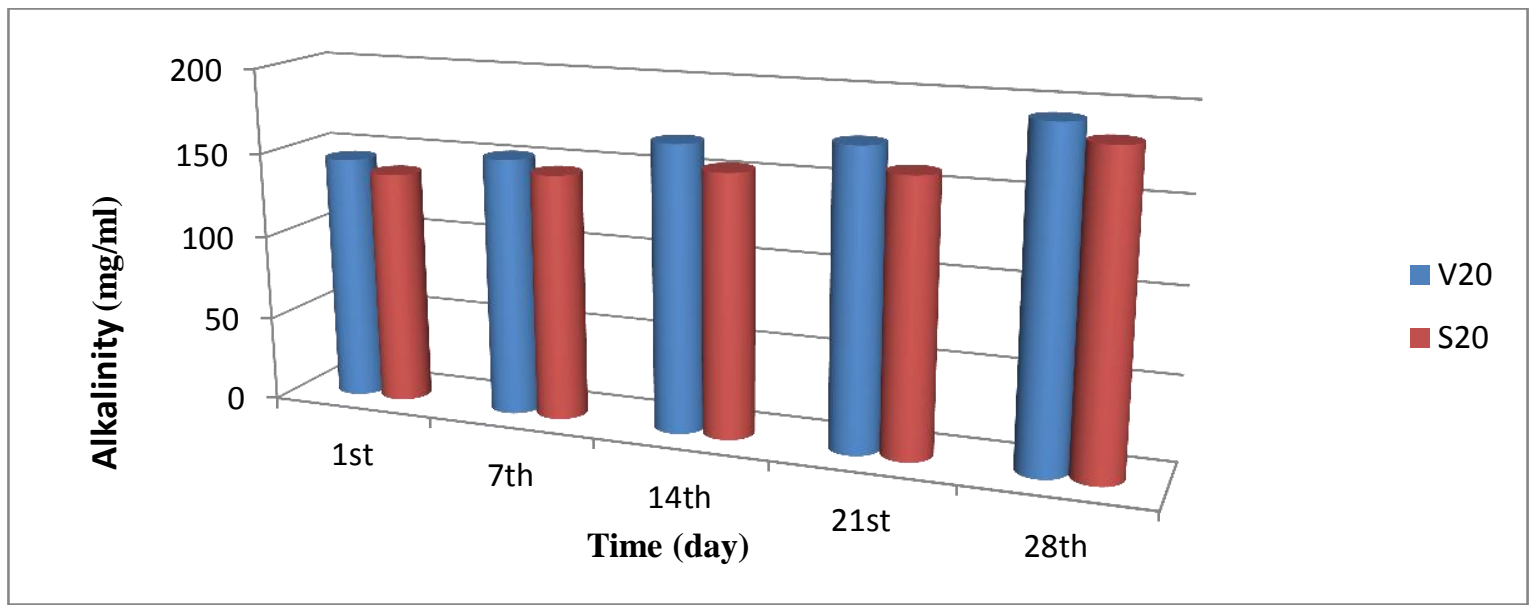

Fig. 10. Change in alkalinity of the test systems.

\section{Results}

The dilution on which the values were equivalent or almost equivalent to the control were considered as the non toxic concentration as in $0.01 \mathrm{mg} / \mathrm{ml}$ in the table. The characteristics and identities of the fungal isolates from the various oils include the general; Aspergillus, Fusarium, Mucor, Penicillium, Rhizopus, and Saccharomyces. The results of the physicochemical analyses for the various engine oils for the period of 28 days are showed in the figures above. The $\mathrm{pH}$ obtained in comparison on the first day and twenty-eight day apparently decreased from 6,2 to 4.9. Observation showed that the percentage change in total organic carbon value (0.626) for $\mathrm{V} 20$ at the first day shows that $30.03 \%$ remained after 28 days. This means that it is apparently the least degradable sample while the TOC value (0.622) for S20 had $16.24 \%$ remaining after 28 days which apparently the highest degradable sample. The decrease during the 28 days biodegradation process 
observed for the parameters indicated that there were active utilization of oxygen and other nutrients available in the test system. The $\mathrm{pH}$ profile obtained generally fell between the optimum range of 4.9 and 6.2 which favors most of the fungi, it showed that microorganisms utilizing hydrocarbon as nutrient produce metabolic products. These metabolic products must have contributed to the reduction in $\mathrm{pH}$ readings. It was also observed that the nutrients (sulphate, phosphate and nitrate) decreased considerably with time as the research elapses. The decrease is understandable as they were used in the metabolism of microorganism in building biomass. There also a correspondence in the utilization of phosphate, sulphate and nitrate indicating their relative importance in cell metabolism as stated by Odum's combine law. The biochemical oxygen demand (BOD) of the media were decreasing as the study progressed indicating that the oxygen content in the medium is been utilized by the heterotrophic fungi.

\section{Conclusion}

Engine oils have been found to be susceptible to microbial attack and hence biodegradation or even biodeterioration of unused engine oils can occur. Microorganisms are known to attack engine oils [14]. The fungal isolates identified as Aspergillus, Fusarium, Mucor, Penicillium, Rhizopus, and Saccharomyces has been reported to degrade petroleum products [7,9]. There were appropriate fungal populations in the samples, hydrocarbon degradation were near impossible if necessary nutrients were not available. It is well established that the availability of nitrogen and phosphorus limit the microbial degradation of hydrocarbons [11]. From the graphs, it was observed that the phases of growth followed a normal batch growth curve pattern. The results of the research have shown that the degradability of the engine oils by fungi were positive and in accordance with the previous researches. Time series degradation processes by indigenous microorganisms from the soil have shown to be relatively efficient in the breaking down of petroleum products as evidently indicated by the physicochemical analysis.

\section{References}

[1]. Amanchukwu S.C., Obafemi A. and Okpokwasili, G.C. (1989). Hydrocarbon Degradation and Utilization by Palm Wine Yeast Isolates.FEMS Microbiol. Letters 57: 151-154.

[2]. Anthony and Okoh (2006). Biodegradation Alternative in the Cleanup of Petroleum Hydrocarbon Pollutants.Biotechnol. Mol. Biol. 1: $38-50$.

[3]. Chaillan F., Chaineau C. H. Point V., Saliot A., and Oudot J. (2006). Factors Inhibiting Bioremediation of Soil Contaminated with Weathered Oils and Drill Cuttings. Env. Pol 144: 255-265.

[4]. Chaineau C. H., Rougeux G., Yepremian C. and Oudot J. (2005). Effects of Nutrient Concentration on the Biodegradation of Crude Oil and Associated Microbial Populations in the Soil.Soil Biol. And Biochem.37: 1490-1497).

[5]. Cheesbrough M. (2006). District Laboratory Practice in Tropical Countries. McGraw Hill Publishers, New York.pp 143-156.

[6]. Fought J. M. and Westlake D. W. S. (1988). Degradation of Polycyclic Aromatic Hydrocarbon and Aromatic HeterocyclesBy Pseudomonas species. Can. J. Microbiol.34: 1135-1141.

[7]. Hill E.C. (1978). Microbial Degradation of Marine Lubricants, Its Detection and Control.Trans. Inst. Marine Engrs. 90: 197-216.

[8]. Lageman R., Clarke R. and Pool W. (2005). Electro-reclamation, A Versatile Soil Remediation Solution.Eng. Geol. 77: 191-201.

[9]. Mishra S., Jyot J., Kuhad R. C. and Lal B. (2001). Evaluation of Inoculums Addition to Stimulatein situ Bioremediation of Oil Sludge Contaminated Soil. Appl. Env. Microbiol. 67: 1675-1681.

[10]. Naylor, T. W., Brown L. A. and Powell K. A. (1982). Microbiological Investigation of Turbine Oil Spillage.Trib. Int. 15 : $182-186$.

[11]. Odokuma L. O. and Dickson A. A. (2003). Bioremediation of Oil Polluted Mangrove Environment. JESEM. 7: 23-30.

[12]. Odokuma L. O. and Okpokwasili G. C. (1993). Role of Composition in the Degradability of Oil Spill Dispersants.Waste Manage. 12: 39-43.

[13]. Okpokwasili G. C. and Okorie B. B. (1988). Biodeterioration Potentials of Microorganisms Isolated from Car Engine Lubricating Oil. Trib. Int. 21: 215-220

[14]. Okpokwasili G. C. and Okorie B. B. (1991). Influence of Physicochemical Stress of Biodegradability of Car Engine Lubricating Oil.Int. Bioter. 27: 255-264.

[15]. Pala M. D, De Carvalho D., Pinto J. C, Sant Anna G. L (2006). A Suitable Model to Describe Bioremediation of a Petroleum Contaminated Soil. J.Int.Biodeter and Biodegr. 58(6):254-260. 